\title{
Preclinical in vitro models from genetically engineered mice for breast and colon cancer (Review)
}

\author{
NITIN TELANG ${ }^{1}$ and MEENA KATDARE ${ }^{2}$ \\ ${ }^{1}$ Palindrome Liaisons, Montvale, NJ; ${ }^{2}$ Skin of Color Research Institute, Hampton University, Hampton, VA, USA
}

Received December 10, 2010; Accepted February 7, 2011

DOI: 10.3892/or.2011.1215

\begin{abstract}
Genetically engineered mice with targeted alterations in clinically relevant oncogenes, tumor suppressor genes or DNA mismatch repair genes provide unique predictive animal models for human carcinogenesis, and cancer prevention/ therapy. However, some of the genetically engineered mouse models lack target organ specificity for colon carcinogenesis. We have established, characterized and validated stable epithelial cell lines from 'normal' and 'genetically' predisposed target organs that offer innovative and mechanistic approaches, complementing in vivo studies on existing animal models for clinical breast and colon cancer. Epithelial cell lines with upregulated Ras or myc oncogene, mutated Apc tumor suppressor gene and $\mathrm{Mlh}_{1}$ DNA mismatch repair gene provide facile experimental systems for organ site carcinogenesis and cancer prevention. Altered expression of cancer specific biomarkers and their modulation by several synthetic pharmacological agents such as retinoids, selective estrogen receptor modulators, non-steroidal anti-inflammatory drugs and specific enzyme inhibitors have been reported from our laboratory. Oncogene expressing MMEC-Ras and MMEC-myc mammary epithelial cells, Apc mutant $850^{\mathrm{Min}} \mathrm{COL}$ and $1638 \mathrm{~N}$ COL, and DNA mismatch repair/Apc mutant $\mathrm{Mlh}_{1} / 1638 \mathrm{~N}$ COL colon epithelial cells exhibit aberrant cell cycle progression, down-regulated apoptosis and enhanced carcinogenic risk in vitro and tumor formation in vivo. We have reported that relative to the parental 'normal' non-neoplastic cells, genetically 'altered' pre-neoplastic cells exhibit enhanced sensitivity for growth arrest by multiple mechanistically distinct pharmacological agents. Comparative experiments on isogenic 'normal' and genetically 'altered' target cell lines facilitate cancer selective efficacy and identification of susceptible mechanistic pathways. Treatment of these genetically 'altered' pre-neoplastic cells with low dose combi-
\end{abstract}

Correspondence to: Dr Nitin Telang, Cancer Prevention Research Program, Palindrome Liaisons, 10 Rolling Ridge Road, Suite B, Montvale, NJ 07645-1559, USA

E-mail: entitytoo@cs.com

Dr Meena Katdare, Skin of Color Research Institute, Hampton University, PO Box 6035, Hampton, VA 23668, USA

E-mail: meena.katdare@hamptonu.edu

Key words: genetically altered epithelial cells, cancer risk nation of mechanistically distinct pharmacological agents as well as naturally occurring phytochemicals induce cytostatic growth arrest, alter cell cycle progression and reduce carcinogenic risk. The availability of validated technology for model development, and for mechanism based biomarker assays now establishes a novel platform to rapidly test carcinogenicity and preventive/therapeutic efficacy of novel pharmacological agents as well as naturally occurring phytochemicals. Thus, these data permit rational prioritization of efficacious lead compounds for preclinical testing and future clinical trials for prevention/ therapy of breast and colon cancer.

\section{Contents}

1. Introduction

2. Preclinical cell culture models for genetically predisposed breast and colon cancer

3. Biomarkers for carcinogenic risk

4. Chemopreventive test compounds

5. Combinatorial preventive efficacy

6. Conclusions and future directions

\section{Introduction}

Breast and colon cancer together represent prevalent cause of mortality in the US population. Recent estimates by the American Cancer Society have projected 192,370 new cases of breast cancer and 106,100 new cases of colon cancer in 2009 (1). This survey has also projected 40,170 breast cancer related deaths and 49,920 colon cancer related deaths. The life time risk for breast and colon cancer is thus estimated to be 1 in 8 and 1 in 19, respectively. These actuarial data emphasize a persistent need for identifying specific and sensitive biomarkers for carcinogenic risk, and also for safe and effective interventional modalities.

Several elegant observations have provided scientifically robust support to the concept that gain of function mutations in oncogenes and loss of function mutations in the tumor suppressor genes represent primary predisposing genetic defects in breast and colon cancer (2-8). In accord, several genetically engineered mouse models have been developed and characterized to represent well established predictive pre-clinical animal models for clinical breast and colon cancer (5-8). 
Table I. Biomarkers for aberrant proliferation and carcinogenic risk in oncogene transfected mammary epithelial cells.

\begin{tabular}{lccc}
\hline & \multicolumn{3}{c}{ Cell line } \\
\cline { 2 - 4 } Biomarker & MMEC & MMEC-Ras & MMEC-Myc \\
\hline${\text { Population doubling }(\mathrm{h})^{\mathrm{a}}}^{\mathrm{a}}+\mathrm{G}_{2} / \mathrm{M}^{\mathrm{s}}$ subG $_{0}{ }^{\mathrm{b}}$ & 24.0 & 16.4 & 18.3 \\
Anchorage-independent $_{\text {colony }^{\mathrm{c}}}$ & $1.8 \pm 0.5$ & $9.1 \pm 0.3$ & $9.8 \pm 0.6$ \\
Tumorigenicity $^{\mathrm{d}}$ & $0.5 \pm 0.2$ & $27.2 \pm 4.0$ & $28.0 \pm 2.0$ \\
Tumor latency & $0 / 10$ & $9 / 10$ & $10 / 10$ \\
\hline
\end{tabular}

${ }^{a}$ Determined at the exponential growth phase, ${ }^{b}$ determined by flow cytometry, ${ }^{c}$ average number of colonies at day 14 post-seeding, ${ }^{\mathrm{d}}$ determined by mammary fat pad transplantation.

Conventional treatment options for breast and colon cancer continue to be chemo-endocrine therapy for breast and chemotherapy for colon. However, conventional long-term therapeutic interventional modalities are frequently associated with acquired tumor resistance and adverse systemic toxicity, compromising patient compliance (9-14).

Genetically engineered mouse models have also been extensively used as mechanism based screens to identify novel preventive/therapeutic interventional modalities $(15,16)$. However, the genetically engineered mouse models for familial adenomatous polyposis (FAP) and hereditary non-polyposis colon cancer (HNPCC) syndromes that express germ line mutations in clinically relevant tumor suppressor gene and/or DNA mismatch repair genes exhibit carcinogenesis predominantly in the small intestine, rather than in the colon (4,6-8), while clinical FAP and HNPCC syndromes represent high risk lesions for colon cancer $(3,4)$. Thus, these in vivo approaches are frequently associated with conceptual and technical limitations related to clinical translatability of the generated data.

Cell culture models developed from target tissue for organ site cancer that express clinically relevant genetic defects and exhibit quantifiable risk for carcinogenesis, thus represent an alternative approach that complements existing animal models for rapid mechanism based prioritization of efficacious preventive/ therapeutic agents.

In the progressive pathogenesis of organ site cancer of breast and colon, intra-epithelial neoplasia such as ductal carcinoma in situ (DCIS) of the breast and adenoma of the colon have been considered as definitive pre-invasive lesions at risk for invasive cancer $(2-4,17)$.

At the molecular level, DCIS are characterized by the presence or absence of hormone receptors and over expression/ mutation of select genes such as Ras, myc, HER-2 and p53, and therefore, exhibit variable response to chemo-endocrine therapy $(2,17,18)$. The colonic adenomas are characterized by germ line or somatic mutations in tumor suppressor adenomatous polyposis coli (APC) gene or in select DNA mismatch repair genes that are associated with high risk familial adenomatous polyposis (FAP) or hereditary non-polyposis cancer (HNPCC) syndromes, respectively $(3,4)$.

Chemoprevention of these epithelial organ site cancers of breast and colon, using synthetic pharmacological agents or naturally occurring compounds individually or in combination to inhibit, reduce or delay the multi-step carcinogenic process has attracted intense clinical interest. Thus, the ability of chemopreventive agents at low non-toxic levels to target early occurring carcinogenic events represents a major promise of current clinical preventive intervention $(18,19)$.

The present review summarizes the data generated from our experiments designed to i) develop cell culture models from genetically engineered mice predisposed to breast and colon cancer, ii) identify specific and sensitive surrogate endpoint biomarkers for loss of homeostatic growth control and gain of carcinogenic risk, and iii) validate the developed cell culture based approaches as rapid screens for efficacious preventive/ therapeutic agents.

\section{Preclinical cell culture models for genetically predisposed breast and colon cancer}

Breast. Aberrant expression of select oncogenes such as Ras, myc or HER-2 has been detected in several clinical organ site cancers including breast cancer (2,17-19). Similarly, targeted expression of these individual oncogenes in genetically engineered mice is associated with mammary carcinogenesis (5,15-17), and more importantly, stable transfection of these oncogenes in non-tumorigenic mammary epithelial cells is sufficient to induce multi-step tumorigenic transformation (20-22). With an objective of developing a cell culture model for oncogene-induced mammary carcinogenesis, we established stable transfectants from immortalized non-tumorigenic mouse mammary epithelial cells (MMEC) that were transfected independently with EJ-Ras and c-myc oncogenes and characterized the resultant MMEC-Ras and MMEC-myc cell lines $(20,21)$.

Colon. Germ line mutations in the APC tumor suppressor gene represent a primary genetic defect in the FAP syndrome $(3,4)$, while those in select DNA mismatch repair genes such as $\mathrm{Mlh}_{1}$ represent a primary genetic defect in the HNPCC syndrome (4). Both these syndromes are associated with genetic predisposition for early onset familial/hereditary colon cancer $(15,16)$. Genetically engineered mice carrying Apc and/or Apc plus DNA mismatch gene mutations exhibit high risk for 
Table II. Biomarkers for aberrant proliferation and carcinogenic risk in mutant colon epithelial cells.

\begin{tabular}{|c|c|c|c|c|c|}
\hline \multirow[b]{2}{*}{ Biomarker } & \multicolumn{5}{|c|}{ Cell Line } \\
\hline & C57 COL & $850^{\mathrm{Min}} \mathrm{COL}$ & $1638 \mathrm{~N}$ COL & $\mathrm{Mlh}_{1} \mathrm{COL}$ & $\begin{array}{c}\mathrm{Mlh}_{1} / 1638 \mathrm{~N} \\
\mathrm{COL}\end{array}$ \\
\hline Population doubling $^{\mathrm{a}}$ & 34 & 16 & 17 & 29 & 20 \\
\hline $\mathrm{S}+\mathrm{G}_{2} / \mathrm{M}: \mathrm{subG}_{0}^{\mathrm{b}}$ & $5.7 \pm 0.3$ & $31.9 \pm 6.2$ & $29.9 \pm 1.2$ & $4.7 \pm 1.2$ & $11.1 \pm 1.2$ \\
\hline $\begin{array}{l}\text { Anchorage-independent } \\
\text { colonies }^{c}\end{array}$ & $0.8 \pm 0.5$ & $18.9 \pm 2.5$ & $17.7 \pm 2.3$ & $0.6 \pm 0.3$ & $13.7 \pm 1.8$ \\
\hline Tumorigenicity $^{\mathrm{d}}$ & $0 / 10$ & $10 / 10$ & $10 / 10$ & $0 / 10$ & $8 / 10$ \\
\hline Tumor latency & 24 weeks & 5-8 weeks & 8-10 weeks & 24 weeks & 10-14 weeks \\
\hline
\end{tabular}

${ }^{\mathrm{a}}$ Determined at the exponential growth phase, ${ }^{\mathrm{b}}$ determined by flow cytometry, ${ }^{\mathrm{c}}$ average number of colonies at day 14 post seeding, ${ }^{\mathrm{d}}$ determined by sub-cutaneous transplantation.

Table III. Selective efficacy of chemo-preventive test compounds in mammary and colon epithelial cells.

\begin{tabular}{lcc}
\hline $\begin{array}{l}\text { Mammary epithelial } \\
\text { cell line }\end{array}$ & $\begin{array}{c}\text { Inhibitory concentration } \\
\left(\mathrm{IC}_{50} \mu \mathrm{M}\right)^{\mathrm{a}}\end{array}$ \\
\hline & 4-HPR & TAM \\
\hline MMEC & 7.9 & 16.7 \\
MMEC-Ras & 2.8 & 6.2 \\
MMEC-Myc & 2.5 & 4.7 \\
Colon epithelial & & \\
cell line & SUL & DFMO \\
C57 COL & 57.5 & 5.8 \\
850 & 11.2 & 32.8 \\
1638N COL & 16.7 & 38.6 \\
Mlh $_{1}$ COL & 39.3 & 35.7 \\
Mlh $_{1} / 1638 \mathrm{~N}$ COL & 14.3 & \\
\hline
\end{tabular}

${ }^{a}$ Extrapolated from cell viability at day 5 post-seeding from dose response of $5 \log \mu \mathrm{M}(0.01-100 \mu \mathrm{M})$ concentration range.

intestinal cancer $(6-8,15,16)$. In an effort to develop preclinical in vitro colon epithelial cell culture models for FAP and HNPCC syndromes, we used histopathologically normal descending colon (a target organ site for colon cancer) from Apc mutant Apc850 $0^{\mathrm{Min}} /+$, Apc $1638 \mathrm{~N}^{[+/]}$, and $\mathrm{Mlh}_{1}{ }^{[+-/]} / 1638 \mathrm{~N}^{[+/-]}$mice to establish and characterize $850^{\mathrm{Min}} \mathrm{COL}, 1638 \mathrm{~N} \mathrm{COL}$ and $\mathrm{Mlh}_{1} /$ 1638N COL cell lines, respectively (23-26).

\section{Biomarkers for carcinogenic risk}

Loss of homeostatic growth control and gain of carcinogenic risk together characterize the pre-neoplastically transformed cells. Population doubling time, and status of proliferative and apoptotic cell populations represent the end point biomarkers for homeostatic growth control, while anchorage-independent growth and tumorigenecity represent the end point biomarker for carcinogenic risk.

Breast. The data generated from the experiments on mamary epithelial cells MMEC, MMEC-Ras and MMEC-myc are summarized in Table I. These data demonstrate that oncogene transfected cell lines exhibit $23.7-31.7 \%$ decrease in the population doubling time, relative to the parental MMEC cells. Furthermore, these transfected cells also exhibit 4.0- to 4.4- fold increase in the ratio of proliferative $\left(S+G_{2} / M\right)$ versus apoptotic $\left(\mathrm{subG}_{0}\right.$ ) cell population due to increased proliferation and decreased cellular apoptosis. These data provided evidence that aberrant proliferation and down-regulated apoptosis lead to the loss of homeostatic growth control in oncogene transfected mammary epithelial MMEC-Ras and MMEC-myc cells.

The Ras and myc oncogene transfected cells exhibit 53.4to 55.0-fold increase in the number of anchorage-independent (AI) colonies and greater than 90\% incidence of tumors, 3-5 weeks post-transplantation. In contrast, the parental MMEC cells lack anchorage-independent colony formation and tumorigenicity. These data are consistent with several previous publications (20-22) and provide evidence for gain of carcinogenic risk in the oncogene transfected mammary epithelial cells.

Colon. The data generated in the cell lines C57 COL (Apc ${ }^{[+++] /}$ $\mathrm{Mlh}_{1}{ }^{[+++]}$), 850 ${ }^{\mathrm{Min}} \mathrm{COL}, 1638 \mathrm{~N}$ COL (Apc ${ }^{[+/]}$, FAP models), and $\mathrm{Mlh}_{1}$ COL and $\mathrm{Mlh}_{1} / 1638 \mathrm{~N}$ COL $\left(\mathrm{Mlh}_{1}{ }^{[+/-]}\right.$, Apc ${ }^{[+/-]}$, HNPCC model) are summarized in Table II. The cell culture models for FAP syndrome exhibit 50 to $65 \%$ decrease in the population doubling time and 4.2- to 12.7 -fold increase in the $\mathrm{S}+\mathrm{G}_{2} / \mathrm{M}: \mathrm{subG}_{0}$ ratio due to aberrant proliferation and downregulated apoptosis. In the cell culture model for the HNPCC syndrome these end points exhibit $41.2 \%$ decrease and $94.7 \%$ increase, respectively. It was noteworthy that in contrast to the double mutant $\mathrm{Mlh}_{1} / 1638 \mathrm{~N}$ COL cells, the $\mathrm{Mlh}_{1} \mathrm{COL}$ cells containing only the $\mathrm{Mlh}_{1}$ mutation failed to express these perturbed biomarkers that are specific for the loss of homeostatic growth control. 
Table IV. Modulation of cell cycle progression in oncogene transfected mammary epithelial cells.

\begin{tabular}{lccc}
\hline & & \multicolumn{2}{c}{$\mathrm{G}_{1}: \mathrm{S}+\mathrm{G}_{2} / \mathrm{M} \mathrm{ratio}^{\mathrm{a}}$} \\
\cline { 3 - 4 } Treatment & Concentration & MMEC-Ras & MMEC-Myc \\
\hline EtOH & $0.01 \%$ & $0.6 \pm 0.2$ & $0.7 \pm 0.3$ \\
4-HPR & $1 \mu \mathrm{M}$ & $2.1 \pm 0.6^{\mathrm{b}}$ & $5.4 \pm 0.7^{\mathrm{e}}$ \\
TAM & $1 \mu \mathrm{M}$ & $7.3 \pm 0.8^{\mathrm{c}}$ & $7.6 \pm 0.8^{\mathrm{f}}$ \\
4-HPR+TAM & $1+1 \mu \mathrm{M}$ & $9.5 \pm 0.4^{\mathrm{d}}$ & $12.2 \pm 0.6^{\mathrm{g}}$ \\
\hline
\end{tabular}

${ }^{\mathrm{a}}$ Determined at day 5 post-seeding. Mean $\pm \mathrm{SD}, \mathrm{n}=6$ per treatment group. ${ }^{\mathrm{b}-\mathrm{d}, \mathrm{e}-\mathrm{g}} \mathrm{p}=0.001 ;{ }^{\mathrm{c}-\mathrm{d}, \mathrm{f}-\mathrm{g}} \mathrm{p}=0.03$.

The anchorage-independent colony formation representing the surrogate end point biomarker for carcinogenic risk exhibited 19.7-31.1-fold increase in the number of AI colonies in the FAP models and 16.1-fold increase in the HNPCC model. The $\mathrm{Mlh}_{1}$ COL cells did not exhibit anchorage-independent colony formation. The models for FAP and HNPCC syndromes also exhibited $80-100 \%$ incidence of tumors after a latent period of 8-14 weeks post-transplantation. In contrast, the normal C57 COL cells and $\mathrm{Mlh}_{1}$ mutant $\mathrm{Mlh}_{1} \mathrm{COL}$ cells lacked the expression of the biomarker specific for carcinogenic risk. These data on $\mathrm{Mlh}_{1} \mathrm{COL}$ cells suggest that mutation in DNA repair gene alone is not sufficient to increase the carcinogenic risk.

These data taken together indicate that mutations in Apc alone or in both Apc and $\mathrm{Mlh}_{1}$ genes together represent primary genetic defects that are responsible for induction of aberrant proliferation and for predisposition for enhanced carcinogenic risk in the present cell culture models of FAP and HNPCC syndromes, respectively. In contrast, mutation in the $\mathrm{Mlh}_{1}$ gene alone may be insufficient to drive the carcinogenic process. It is noteworthy that mutations and/or other genetic defects in APC together with $\mathrm{MLH}_{1}$ genes have been observed in clinical $\operatorname{HNPCC}(3,4,15,16)$.

\section{Chemopreventive test compounds}

Our previous publications have reported preventive efficacy of several mechanistically distinct pharmacological agents and naturally occurring phytochemicals on developed cell culture model for $\mathrm{ER}^{-} / \mathrm{PR}^{-} / \mathrm{HER}-2^{+}$comedo DCIS that is at risk for developing chemo-endocrine therapy resistant breast cancer (27-30), and on cell culture models for FAP syndrome (23-25) and HNPCC syndrome (26). These test compounds used individually at pharmacologically achievable dose levels, inhibit cell cycle progression, induce cellular apoptosis and reduce carcinogenic risk in all the cell culture models. It is noteworthy that the chemopreventive test compounds selected for present studies have documented evidence of efficacy both as single agents, as well as low dose combinations in the animal model systems and in clinical setting (31-36).

Breast. The experiments designed to examine the growth inhibitory effects of selected chemo-preventive test compounds on the $\mathrm{ER}^{+}$Ras and myc oncogene transfected mammary
A

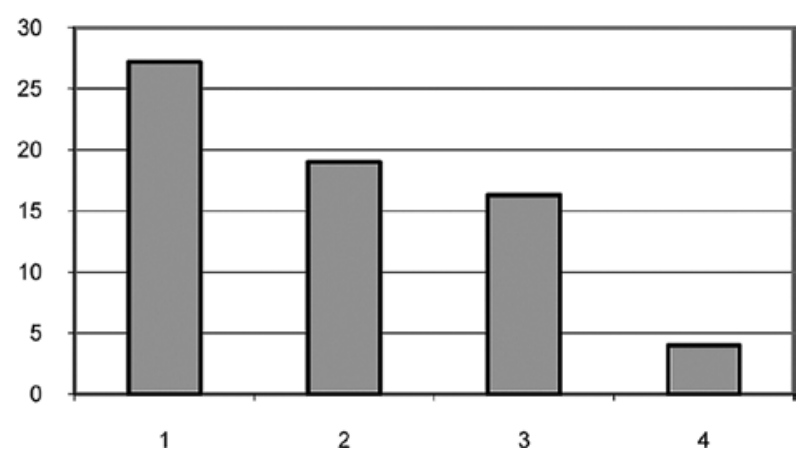

B

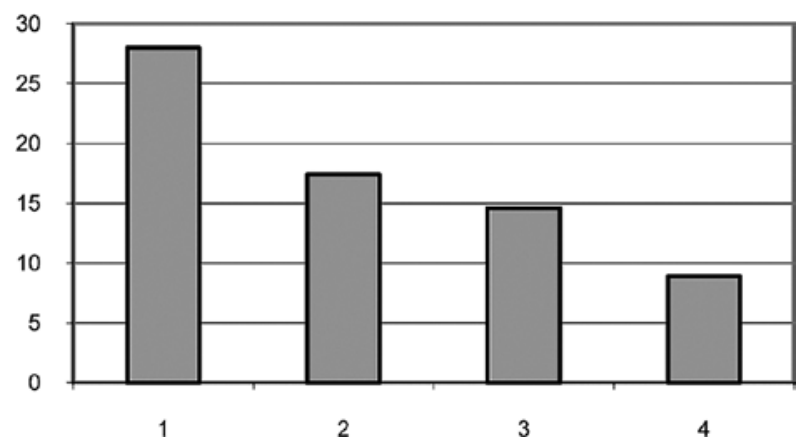

Figure 1. (A and B) Efficacy of $1 \mu \mathrm{M} 4-\mathrm{HPR}+1 \mu \mathrm{M}$ TAM in combination on MMEC-Ras, and MMEC-Myc cells. (A) Anchorage independent colony formation in MMEC-Ras cells. Number of anchorage independent colonies, mean $\pm \mathrm{SD}, \mathrm{n}=12$ per treatment group. (1) EtOH control, (2) 4-HPR, (3) TAM, (4) 4-HPR+TAM. Control versus combination $p=0.001$, single agent versus combination $p=0.01$. (B) Anchorage independent colony formation in MMEC-Myc cells. Number of anchorage independent colonies, mean \pm SD, $\mathrm{n}=12$ per treatment group. (1) EtOH control, (2) 4-HPR, (3) TAM, (4) 4-HPR+TAM. Control versus combination $\mathrm{p}=0.003$, single agent versus combination $\mathrm{p}=0.01$. Note that the combination induces greater reduction in the number of anchorage independent colonies relative to that induced by these agents alone (42)

epithelial cell culture models are summarized in Table III. Clinically relevant synthetic retinoid $\mathrm{N}$-(4-hydroxyphenyl) retinamide (4-HPR) and selective estrogen receptor modulator Tamoxifen (TAM) were selected as the test compounds for the experiments with mammary epithelial cell lines.

The synthetic retinoid 4-HPR functions as a potent inhibitor of reactive oxygen species and has documented efficacy against breast cancers irrespective of their hormone receptor status (31). The selective estrogen receptor modulator TAM has documented selective efficacy against estrogen receptor positive breast cancer (9). It was noteworthy that the oncogene transfected cells exhibited $63-94 \%$ greater sensitivity to growth inhibition relative to that exhibited by the parental cells (Table III).

Colon. Clinically relevant non-steriodal anti-inflammatory drug Sulindac (SUL) and selective orinithine decarboxylase inhibitor Difluoro methylornithine (DFMO) were selected as the test compounds for the experiments with the colon epithelial cell lines (Table III).

The synthetic non-steroidal anti-inflammatory drug, sulindac (SUL), functions as a pan-selective cyclo-oxygenase inhibitor, 
Table V. Modulation of cell cycle progression in mutant colon epithelial cells.

$$
\mathrm{G}_{1}: \mathrm{S}+\mathrm{G}_{2} / \mathrm{M} \mathrm{ratio}^{\mathrm{a}}
$$

\begin{tabular}{lcccc}
\cline { 2 - 4 } Treatment & Concentration & $850^{\text {Min }} \mathrm{COL}$ & $1638 \mathrm{~N} \mathrm{COL}$ & $\mathrm{Mlh}_{1} / 1638 \mathrm{~N} \mathrm{COL}$ \\
\hline EtOH & $0.01 \%$ & $3.1 \pm 0.7$ & $3.3 \pm 0.4$ & $2.7 \pm 0.6$ \\
SUL & $2 \mu \mathrm{M}$ & $5.4 \pm 0.3^{\mathrm{b}}$ & $10.5 \pm 0.6^{\mathrm{e}}$ & $3.6 \pm 0.3^{\mathrm{h}}$ \\
DFMO & $10 \mu \mathrm{M}$ & $8.2 \pm 0.8^{\mathrm{c}}$ & $9.6 \pm 0.6^{\mathrm{f}}$ & $6.8 \pm 0.6^{\mathrm{i}}$ \\
SUL+DFMO & $2+10 \mu \mathrm{M}$ & $12.8 \pm 0.2^{\mathrm{d}}$ & $15.3 \pm 1.0^{\mathrm{g}}$ & $9.6 \pm 0.5^{\mathrm{j}}$ \\
\hline
\end{tabular}

${ }^{\mathrm{a}}$ Determined at day 5 post-seeding. Mean $\pm \mathrm{SD}, \mathrm{n}=6$ per treatment group. ${ }^{\mathrm{b}-\mathrm{d}, \mathrm{i}-\mathrm{j}} \mathrm{p}=0.001$; $^{\mathrm{c}-\mathrm{d}, \mathrm{e}-\mathrm{g}, \mathrm{f}-\mathrm{g}, \mathrm{h}-\mathrm{j}} \mathrm{p}=0.04$.

and has documented efficacy in the FAP syndrome, as well as in sporadic colon cancer (32). The synthetic pharmacological agent difluoro-methylornitine (DFMO) functions as selective inhibitor of ornithine decarboxylase, a critical rate limiting enzyme in polyamine bio-synthetic pathway (33). Cyclooxygenase and ornithine decarboxylase enzymes are up-regulated in colon cancer and therefore, represent important molecular targets for preventive/therapeutic interventions $(18,19,32,33)$.

The colon epithelial cell lines exhibiting genetic defects in Apc alone or in Apc and $\mathrm{Mlh}_{1}$ represent relevant cell culture models for the FAP and HNPCC syndromes, respectively. These models exhibited $49.1-80.5 \%$ greater sensitivity to the test compounds relative to that observed in the C57 COL cell line. In this context, it was noteworthy that consistent with a lack of carcinogenic risk, $\mathrm{Mlh}_{1} \mathrm{COL}$ cells that have mutation only in the $\mathrm{Mlh}_{1}$ DNA mismatch repair gene were substantially less sensitive to the inhibitory effects of the test compounds, than were the models for FAP and HNPCC syndromes.

\section{Combinatorial preventive efficacy}

Several recent reports have demonstrated that low-dose combinations of mechanistically distinct chemo-preventive agents exhibit enhanced efficacy relative to that produced by individual agents at comparative concentrations (34-36).

Breast. To examine the concept of combinatorial preventive efficacy in the developed mammary epithelial cell culture models, low dose combinations of 4-HPR+TAM were used on the oncogene transfected MMEC-Ras and MMEC-myc cells. The efficacy of the combinations was monitored by the status of $\mathrm{G}_{1}: \mathrm{S}+\mathrm{G}_{2} / \mathrm{M}$ ratio (specific for aberrant proliferation) and anchorage independent colony formation (specific for carcinogenic risk).

The data generated from the experiments designed to examine the effect of low dose combination of 4-HPR+TAM on $\mathrm{G}_{1}: \mathrm{S}+\mathrm{G}_{2} / \mathrm{M}$ ratio in MMEC-Ras and MMEC-Myc cells are presented in Table IV. These data demonstrate that in MMECRas cells the 4-HPR+TAM combination is about 3.5-fold and $30 \%$ more efficacious in increasing the $\mathrm{G}_{1}: \mathrm{S}+\mathrm{G}_{2} / \mathrm{M}$ ratio relative to that observed by 4 -HPR or TAM individually at equimolar concentrations. Similarly, the experiment on MMECMyc cells revealed a 1.2 -fold and $60.5 \%$ greater efficacy of the combination relative to individual agents.
The data from the experiments designed to examine the effect of the 4-HPR+TAM combination on anchorage-independent colony formation in two oncogene transfected cell lines are presented in Fig. 1A and B. The AI colony number In MMEC-Ras cells treated with 4-HPR, TAM and 4-HPR+TAM was $19.0 \pm 2.8,16.3 \pm 2.4$ and $4.0 \pm 0.6$, respectively. Thus, in these cells the combination exhibits about $77 \%$ greater efficacy in reduction of $\mathrm{AI}$ colonies relative to that observed by these agents individually at equimolar concentrations. The AI colony number in MMEC-Myc cells treated with 4-HPR, TAM and 4-HPR+TAM was 17.4 $\pm 1.2,14.6 \pm 1.0$ and $8.9 \pm 0.6$, respectively. These data indicated that 4-HPR+TAM combination exhibits about $44 \%$ greater efficacy relative to these agents individually.

Colon. To examine the concept of combinatorial preventive efficacy in the FAP and HNPCC models low-dose combination of SUL+DFMO were utilized. The data generated from experiments to examine the modulation in $\mathrm{G}_{1}: \mathrm{S}+\mathrm{G}_{2} / \mathrm{M}$ ratio by the low dose combination of SUL+DFMO are presented in Table V. In $850^{\text {Min }}$ COL cells the combination of SUL+DFMO exhibit 1.4 -fold and $56.1 \%$ greater efficacy to increase the $\mathrm{G}_{1}: \mathrm{S}+\mathrm{G}_{2} / \mathrm{M}$ ratio relative to that observed by these agents individually. In $1638 \mathrm{~N}$ COL cells the combination exhibits $45.7 \%$ and $59.4 \%$ greater efficacy, while in $\mathrm{Mlh}_{1} / 1638 \mathrm{~N}$ COL cells the combination exhibits 1.7 -fold and $41.2 \%$ greater efficacy.

The data from experiments designed to examine the effect of the SUL+DFMO combination on anchorage-independent colony formation in the three colon epithelial cell lines are presented in Fig. 2A-C. In $850^{\mathrm{Min}} \mathrm{COL}$ cells the AI colony number in SUL, DFMO and SUL+DFMO treated groups was $14.4 \pm 2.4,13.5 \pm 2.2$ and $8.4 \pm 1.4$, respectively. These data indicate that the combination exhibits about $39.7 \%$ greater efficacy in reduction of AI colonies. In 1638N COL cells the AI colony number SUL, DFMO and SUL+DFMO treated groups was $15.7 \pm 2.0,14.2 \pm 1.8$ and $9.8 \pm 1.3$, while that in $\mathrm{Mlh}_{1} / 1638 \mathrm{~N} \mathrm{COL}$ cells was $10.9 \pm 1.3,8.9 \pm 1.1$ and $6.0 \pm 0.7$, respectively. Collectively, these data indicated that in the two cell lines the SUL+DFMO combination exhibits $41.2 \%$ and $38.7 \%$ greater efficacy respectively relative to these agents individually.

\section{Conclusions and future directions}

Preclinical models derived from genetically engineered mice represent valuable predictive models for human organ site 
A

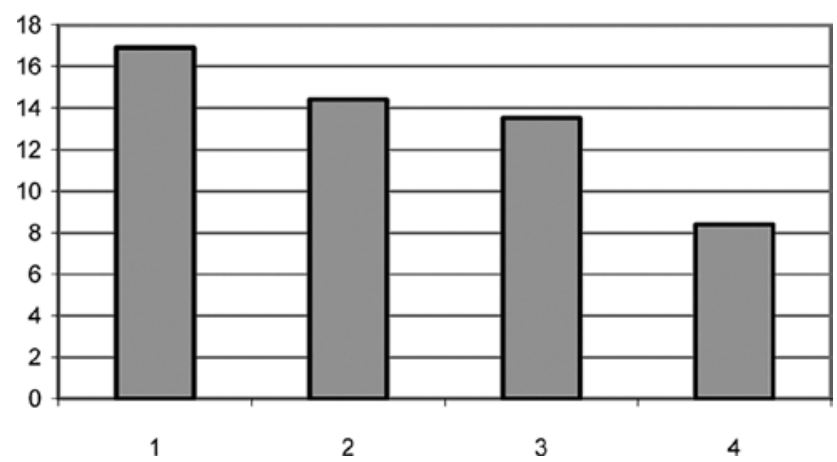

B

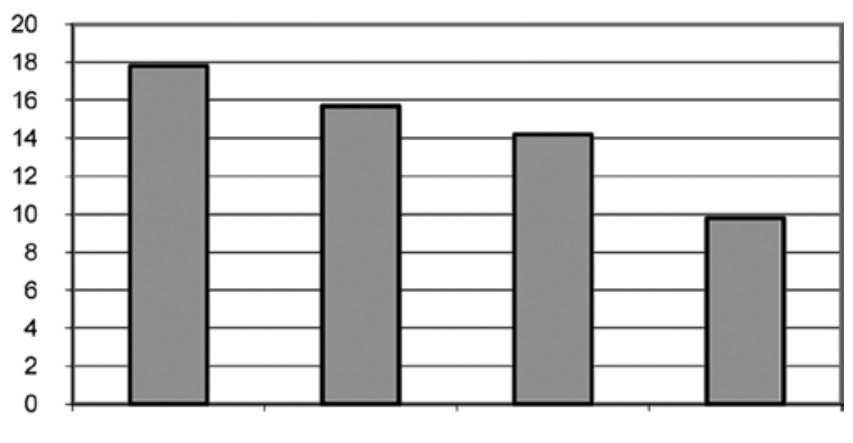

1

4

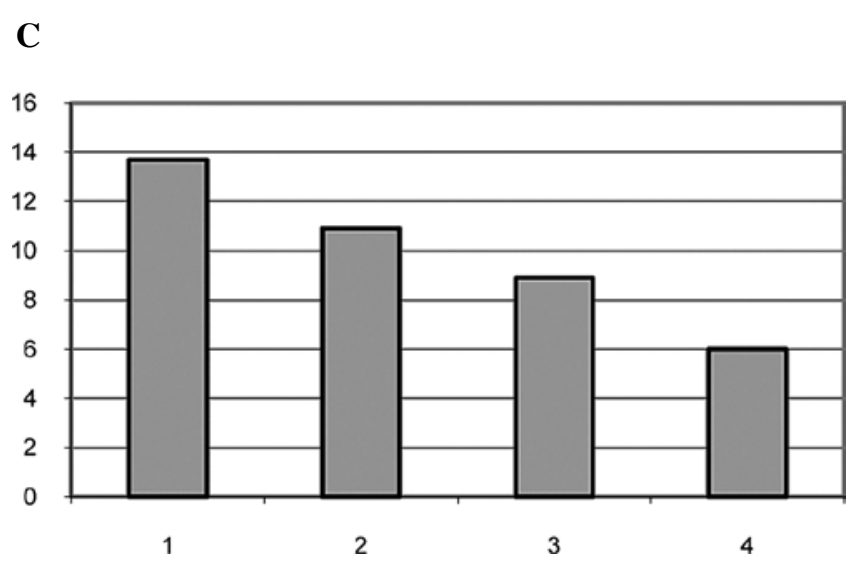

Figure 2. (A-C) Efficacy of $2 \mu \mathrm{M}$ SUL $+10 \mu \mathrm{M}$ DFMO in combination on $850^{\mathrm{Min}} \mathrm{COL}, 1638 \mathrm{~N}$ COL and $\mathrm{Mlh}_{1} / 1638 \mathrm{~N}$ COL cells. (A) Anchorageindependent colony formation in $850^{\mathrm{Min}} \mathrm{COL}$ cells, number of anchorageindependent colonies, mean $\pm \mathrm{SD}, \mathrm{n}=12$ per treatment group. (1) $\mathrm{EtOH}$ control, (2) SUL, (3) DFMO, (4) SUL+DFMO. Control versus combination $p=0.002$. Single agent versus combination $p=0.03$. (B) Anchorage-independen colony formation in $1638 \mathrm{~N}$ COL cells. Number of anchorage-independent colonies, mean $\pm \mathrm{SD}, \mathrm{n}=12$ per treatment group. (1) EtOH control, (2) SUL, (3) DFMO, (4) SUL+DFMO. Control versus combination $\mathrm{p}=0.002$, single agent versus combination $\mathrm{p}=0.03$. (C) Anchorage-independent colony formation in $\mathrm{Mlh}_{1} / 1638 \mathrm{~N}$ COL cells. Number of anchorage-independent colonies, mean \pm SD $n=12$ per treatment group. (1) EtOH control, (2) SUL (3) DFMO, (4) SUL+DFMO. Control versus combination $p=0.002$, single agent versus combination $\mathrm{p}=0.03$. Note that the combination induces greater reduction in the number of anchorage-independent colonies relative to that induced by these agents alone (42).

cancer. Target tissue derived epithelial cell lines expressing clinically relevant genetic defects and exhibiting quantifiable risk for carcinogenesis promise to provide facile experimental approaches that complement the existing animal models.
The data presented for mammary epithelial cell culture models demonstrate that targeted expression of Ras and Myc oncogenes drives the multi-step carcinogenic process by inducing aberrant cell cycle progression, down-regulated cellular apoptosis and anchorage-independent growth in vitro prior to tumor development in vivo. These modulations taken together provide evidence for oncogene mediated loss of homeostatic growth control and gain of carcinogenic risk. Essentially similar modulations in these surrogate end point biomarkers for carcinogenic risk have also been observed in the colonic epithelial cells exhibiting germ line mutations in the tumor suppressor Apc gene and/or in Apc plus DNA mismatch repair genes. The present biological characterization of the newly developed cell culture models now sets the stage for their molecular characterization relevant to the status of Ras, Myc, Apc signaling cascades and DNA repair pathways.

The experiments on the growth inhibitory effects of prototypical chemopreventive test compounds have provided evidence that preneoplastically transformed cells are more sensitive to growth inhibition than the isogenic parental nontransformed cells. The selectivity for chemopreventive efficacy validates these isogenic models as a unique approach for evaluation of mechanistic efficacy of new compounds.

Clinically relevant, mechanistically distinct 4-HPR and TAM for mammary epithelial cell culture models, and SUL and DFMO for colon epithelial cell culture models validate the clinical relevance of the present experimental approach, since these agents have documented preventive/therapeutic efficacy as single agents for clinical breast and colon cancer, respectively $(9,12,13,18,19,31-33)$. Enhanced efficacy of these test compounds at low-dose combinations essentially extends and confirms similar efficacy observed in vivo in the genetically engineered mouse models $(16,35,36)$. The proof of principle evidence obtained from the data on combinatorial preventive efficacy now provides a scientifically robust basis for future mechanistic studies to identify molecular targets critical for enhanced efficacy. Furthermore, these data also validate the present experimental approaches for rapid prioritization of new chemopreventive agents for future animal studies and subsequent clinical trials. In this context it is noteworthy that combinatorial efficacy of SUL+DFMO has been recently reported in a clinical trial on sporadic colon cancer (34).

Recent evidence suggests that cancer initiating stem cells representing therapy resistant minor population may be responsible for frequent acquired tumor resistance to long-term chemo-endocrine therapy in several heterogeneous epithelial organ site cancers (37). Established human breast carcinoma cell lines, such as MCF-7 and T47D as well as clinical breast cancer specimens, exhibit the presence of cancer initiating stem cell population $(37,38)$. Normal target organs for these cancers also exhibit the presence of self renewing, pluripotent stem cell population (39). Recent research on clinical pancreatic adenocarcinoma specimens has demonstrated the presence of CD44 $4^{+/ \text {High }} / \mathrm{CD} 24^{-/ L o w} / \mathrm{ESA}$ enriched stem cells exhibiting the property of self-renewal, ability for production of differentiated progeny and accelerated tumor development (40), and abrogation of stem cell characteristics via synergistic efficacy of a combination of a synthetic multi-kinase inhibitor sorafenib with a naturally occurring NF- $\mathrm{kB}$ inhibitor sulforaphane (41). 
The data generated for the breast epithelial cell lines $(20,21)$, and for the colon epithelial cell lines (23-25) has been recently summarized (42). Thus, in the present context, availability of well characterized breast epithelial cell lines MMEC-Ras and MMEC-Myc, and colon epithelial cell lines $850^{\mathrm{Min}} \mathrm{COL}, 1638 \mathrm{~N}$ $\mathrm{COL}$ and $\mathrm{Mlh}_{1} / 1638 \mathrm{~N}$ COL may represent ideal cell culture systems to generate cancer initiating stem cells and to evaluate their responses to conventional chemo-endocrine therapy. Such unique models promise to identify novel preventive/therapeutic interventions targeted specifically towards therapy resistant carcinogenic stem cell populations.

\section{Acknowledgements}

The current research directions in the Cancer Prevention Research Program have been funded in the past by NCI First Award R29 CA-44741, NCI contracts CN-85141, CN-05107 and $\mathrm{CN}-25111$ under the master agreement MAA NO1-CN-75029-63, and by The Irving Weinstein Foundation. Meena Katdare has been funded in part by NCI P30 CA29502-20 and NCI RO1CA122394. We wish to acknowledge the active participation of Dr Akihiko Suto, Dr Hiroto Ishizuka, Dr Guo Li, in all the research projects on breast and colon chemoprevention, and excellent technical assistance of Milan Zvanovec and Tonye Briggs during the development of the cell culture models.

\section{References}

1. Jemal AR, Segal R, Ward E, et al: Cancer Statistics. Cancer J Clin 58: 71-96, 2008.

2. Martin AM and Weber B: Genetic and hormonal risk factors in breast cancer. J Natl Cancer Inst 92: 1126-1135, 2000.

3. Fearon ER and Vogelstein B: A genetic model for colorectal tumorigenesis. Cell 61: 759-767, 1990.

4. Fodde R, Smits R and Clevers H: APC signal transduction and genetic instability in colon cancer. Nat Rev Cancer 1: 55-67, 2001

5. Stewart TA, Pattengale PK and Leder P: Spontaneous mammary adenocarcinoma in transgenic mice that carry and express MTV/ myc fusion genes. Cell 38: 627-637, 1984.

6. Fodde R, Edelmann W, Yang K, et al: A targeted chain termination mutation in the mouse Apc gene results in multiple intestinal tumors. Proc Natl Acad Sci USA 91: 8969-8973, 1994.

7. Su LK, Kinzler KW, Vogelstein B, et al: Multiple intestinal neoplasia caused by a mutation in the murine homologue of the APC gene. Science 256: 668-670, 1992.

8. Edelmann W, Yang K, Karaguchi M, et al: Tumorigenesis in $\mathrm{Mlh}_{1}$ and $\mathrm{Mlh}_{1} / 1638 \mathrm{~N}$ mice. Cancer Res 59: 1301-1307, 1999.

9. Fisher B, Constantino JP, Wickerman DL, et al: Tamoxifen for prevention of breast cancer: Report of the national surgical adjuvant breast and bowel project (NSABP P-1) study. J Natl Cancer Inst 90: 1371-1388, 1998.

10. Paik S, Bryant J,Park C, et al: ErbB-2 and response to Doxorubicin in patients with axillary lymph node positive, hormone receptor negative breast cancer. J Natl Cancer Inst 90: 1361-1370, 1998.

11. Romond EH, Perez EA, Bryant J, et al: Trastuzumab plus adjuvant chemotherapy of operable HER-2 positive breast cancer. N Engl J Med 353: 1673-1684, 2005.

12. Cuzik J, Powels T, Veronesi U, et al: Overview of main outcomes of breast cancer prevention trials. Lancet 361: 296-300, 2003.

13. Abbruzzese JL and Lippman SM: The convergence of cancer prevention and therapy in early phase clinical drug development. Cancer Cell 6: 321-326, 2004.

14. Solomon SD, McMurrray JJV, Pfeffer MA, et al: Cardiovascular risk associated with celecoxib in a clinical trial for colorectal adenoma prevention. N Engl J Med 352: 1071-1080, 2005.

15. Frese KK and Tuveson DA: Maximizing mouse cancer models. Nat Rev Cancer 7: 645-658, 2007.

16. Abate-Shen C, Brown PH, Colburn NH, et al: The un-taped potential of genetically engineered mouse models in chemoprevention research: Opportunities and challenges. Cancer Prev Res 1: 161-166, 2008.
17. Allred CD, O'Connell $\mathrm{P}$ and Fuqua SAW: Biomarkers in early breast neoplasia. J Cell Biochem 17: 125-131, 1993.

18. O'Shauhnessy JA, Kelloff GJ, Gorden GB, et al: Treatment and prevention of intra-epithelial neoplasia: An important target for accelerated new agent development. Clin Cancer Res 8: 314-346, 2002.

19. Kelloff GJ, Lippman SM, Dannenberg AJ, et al: Progress in chemoprevention drug development: The promise of molecular biomarkers for prevention of intra-epithelial neoplasia and cancer, a plan to move forward. Clin Cancer Res 22: 3661-3697, 2006.

20. Telang NT, Narayanan R, Bradlow HL, et al: Coordinated expression of intermediate biomarkers for tumorigenic transformation in Ras-transfected mouse mammary epithelial cells. Breast Cancer Res Treat 18: 155-163, 1991.

21. Telang NT, Osborne MP, Sweterlitsch LA, et al: Neoplastic transformation of mouse mammary epithelial cells by deregulated c-myc expression. Cell Regulation 1: 863-872, 1990.

22. Zhai YF, Beittenmiller H, Wang B, et al: Increased expression of specific tyrosine phosphatases in human breast epithelial cells neoplastically transformed by the neu oncogene. Cancer Res 53: 2272-2278, 1993.

23. Telang $\mathrm{N}$ and Katdare M: Combinatorial prevention of carcinogenic risk in a model for familial colon cancer. Oncol Rep 17: 909-914, 2007.

24. Telang N and Katdare M: Novel cell culture model for prevention of carcinogenic risk in familial adenomatous polyposis syndrome. Oncol Rep 21: 1017-1021, 2009.

25. Katdare M, Kopelovich L and Telang N: Efficacy of chemopreventive agents on growth inhibition of Apc [+/-] 1638N COL colonic epithelial cells. Int J Mol Med 10: 427-432, 2002.

26. Telang NT, Li G and Katdare M: Prevention of early onset familial/hereditary colon cancer: New models and biomarkers (Review). Int J Oncol 28: 1523-1529, 2006.

27. Subbaramaiah K, Chung WJ, Michaluart P, et al: Resveratrol inhibits cyclo-oxygenase-2 transcription and activity in phorbol ester treated human mammary epithelial cells. J Biol Chem 273 . 21875-21882, 1998.

28. Jinno H, Steiner MG, Nason-Burchenal K, et al: Preventive efficacy of receptor class selective retinoids on HER-2 oncogene expressing preneoplastic human mammary epithelial cells. Int J Oncol 21: 127-134, 2002.

29. Katdare M, Osborne MP and Telang NT: Soy isoflavone genestein modulates cell cycle progression and induces apoptosis in HER-2/ neu oncogene expressing human breast epithelial cells. Int J Oncol 21: 809-816, 2002.

30. Katdare M, Osborne MP and Telang NT: Novel cell culture models for prevention of human breast cancer (Review). Int J Oncol 22: 509-515, 2003

31. Veronesi U, DePalo G, Costa A, et al: Chemoprevention of breast cancer with retinoids. J Natl Cancer Inst 12: 93-97, 1992.

32. Giardiello FM, Hamilton SR, Krush AH, et al: Treatment of colonic and rectal adenoma with Sulindac in familial adenomatous polyposis. N Engl J Med 328: 1313-1316, 1993.

33. Gerner EW and Meyskens FL: Polyamines and cancer: Old molecules, new understanding. Nat Rev Cancer 4: 785-792, 2004.

34. Meyskens FL, McLaren CE,PetotD, et al: Difluoro-methylornithine plus Sulndac for prevention of sporadic colorectal adenomas: a randomized placebo controlled double blind trial. Cancer Prev Res 1: 32-38, 2008.

35. Jacoby RF, Cole CE, Tutsch K, et al: Chemopreventive efficacy of combined Piroxicam and Difluoro-methylornithine on Apc mutant mouse adenoma and selective toxicity against mutant embryos. Cancer Res 60: 1864-1870, 2000.

36. Swamy MV, Patlolla JMR, Steele VE, et al: Chemoprevention of familial adenomatous polyposis by low doses of Atorvastatin and Celecoxib individually and in combination to ApcMin mice. Cancer Res 66: 7370-7377, 2006.

37. Dean M,Fojo T and Bates S: Tumor stem cells and drug resistance. Nat Rev Cancer 5: 275-284, 2005.

38. Al-Hajj M, Wicha MS, Benito-Hernandez A, et al: Prospective identification of tumorigenic breast cancer cells. Proc Natl Acad Sci USA 100: 3983-3988, 2003.

39. Moore KA and Lemishka IR: Stem cells and their niches. Science 311: 1880-1885, 2006.

40. Li C, Heidt DG, Dalerba P, et al: Identification of pancreatic cancer stem cells. Cancer Res 67: 1030-1037, 2007.

41. Rausch V, Liu 1, Kallifatidis G, et al: Synergistic activity of Sorafenib and Sulforaphane abolishes pancreatic cancer stem cell characteristics. Cancer Res 70: 5004-5013, 2010.

42. Telang $\mathrm{N}$ and Katdare $\mathrm{M}$ : Breast and colon cell lines from genetically engineered mice: Novel in vitro models for carcinogenesis and cancer prevention. Int J Mol Med 24: S17, 2009. 